\title{
Efektivitas Metode Talaqqi pada Halaqah Tarbiyah di Wahdah Islamiyah Sulawesi Tenggara dan Analisis Metode Talaqqi dalam Kitab 'Uddatu At Talabi Binajmi Manhaj At Talaqqi Wa Al Adab
}

\author{
Mariyanto Nur Shamsul ${ }^{1 *}$, Iskandar Kato², Samsuddin La Hanufi ${ }^{3}$ \\ $1^{\star}$ Politeknik Bau Bau, Indonesia \\ 2Sekolah Tinggi IImu Islam dan Bahasa Arab (STIBA) Makassar, Indonesia \\ ${ }^{3}$ Sekolah Tinggi Agama Islam Al-Hidayah Bogor, Indonesia \\ *Korespondensi: mariantonurshamsul@yahoo.co.id
}

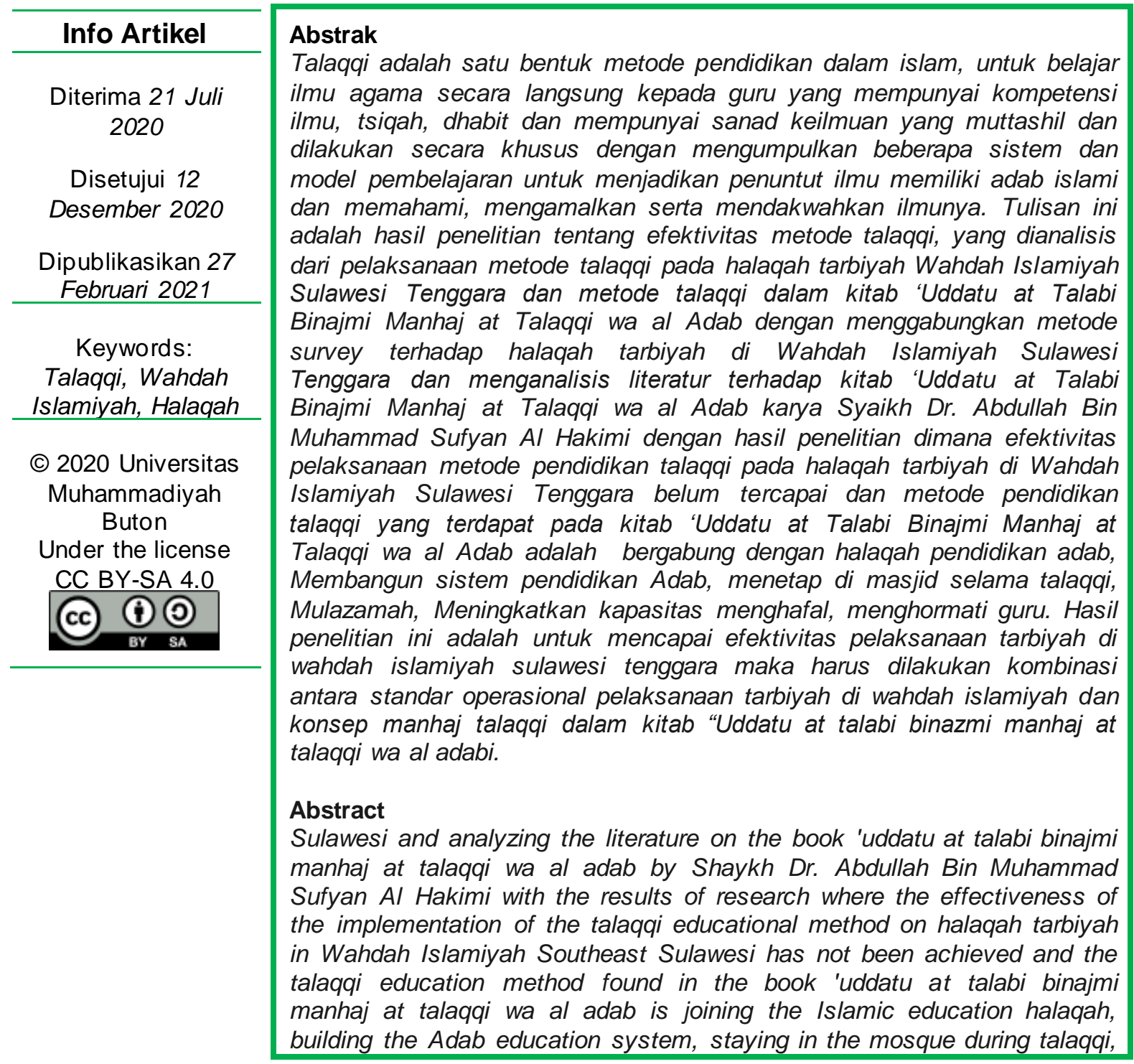




\begin{abstract}
Mulazamah (living with the teacher), and the existing talaqqi education methods in the book 'uddatu at talabi binajmi manhaj at talaqqi wa al adab is Joining the adab education halaqah, building the Adab education system, staying in the mosque during talaqqi, Mulazamah (living with the teacher Increase the capacity to memorize, respect the teacher / shaykh. So the results of this study are to achieve the effectiveness of the implementation of tarbiyah in Wahdah Islamiyah, Southeast Sulawesi, a combination of operational standards for implementing tarbiyah in Wahdah Islamiyah must be carried out and the concept of manhaj talaqqi in the book "Uddatu at talabi binazmi manhaj at talaqqi wa al adabi
\end{abstract}

\title{
1. Pendahuluan
}

Dalam konteks pendidikan islam terdapat metode pendidikan yang telah dilakukan sejak Rasulullah Muhammad SAW dan secara terus menerus dilaku kan oleh para sahabat Rasulullah, tabi'in, tabi'ut taibi'in, sampai kepada para ulama kontemporer dan metode ini melahirkan para pelajar (penuntutilmu) yang memiliki kapasitas ilmu dan adab yang berkualitas, metode yang dimaksud adalah metode "Talaqqi".

Secara bahasa لَّى تَلَقى يَتَكَّى (laqa - talaqqa - yatalaqqaa) Berarti bertemumenemui-berjumpa kemudian menjadi menerima-mengambil-mendapatkan. Jadi Talaqqi adalah salah satu metode untuk mengetahui sesuatu atau bisa di katakan Talaqqi merupakan salah satu metode pembelajaran zaman dulu yang ada hingga saat ini. Talaqqi adalah salah satu metode mengajar peninggalan Nabi Muhammad SAW yang terus menerus dilakukan oleh orang-orang setelah Nabi Muhammad SAW, para sahabat, tabi'in, hingga para ulama bahkan pada zaman sekarang terutama untuk daerah Arab seperti Mekkah, Madinah dan Mesir.

Sudah menjadi hal yang masyhur di kalangan mahasiswa Al- Azhar Mesir terutama cara belajar menggunakan metode talaqqi, yaitu cara pertemuan guru dan murid secara face to face, dari situ para mahasiswa mengambil pelajaran di samping belajar di universitas masing-masing. dilihat dari sistem mengajarnya, maka ada dua macam kategori talaqqi. Pertama, seorang guru membaca atau menyampaikan ilmunya di depan murid-muridnya sedang para murid menyimaknya, yang mungkin di akhiri dengan pertanyaan-pertanyaan. Kedua, murid membaca di depan guru lalu guru membenarkan jika ada kesalahan dalam bacaan murid (Farid, 2011).

Talaqqi merupakan salah satu bentuk metode pendidikan dalam islam untuk belajar ilmu agama secara langsung kepada guru yang mempunyai kompetensi ilmu, tsiqah, dhabit dan mempunyai sanad keilmuan yang muttashil sampai ke Rasulullah SAW melalui para 'Ulama, 'Aalimin, dan 'Aarifin yang dilakukan secara khusus dengan mengumpulkan beberapa sistem dan model pembelajaran untuk menjadikan penuntut ilmu memiliki adab islami dan memahami, mengamalkan serta mendakwahkan ilmunya (Al-Gazali, 2005). Talaqqi juga memilki arti yakni belajar ilmu agama secara langsung kepada guru atau pertemuan antara murid dengan guru secara langsung secara berhadapan, guru mengucapkan, dan mu rid mengikuti, sembari menghafal di depan gurunya, dimana guru tersebut mempunyai kompetensi ilmu, tsiqah, dhabit dan mempunyai sanad keilmuan yang muttasil sampai ke Rasulullah Shallahu 'Alaihi Wa Sallam melalui para Ulama Alimin Arifin (Abdullah, 1429). 
Di zaman Nabi Muhammad SAW. sendiri talaqqi kedua hanya bisa digunakan dalam membaca AI-Quran, yaitu para sahabat membaca al-Quran didepan Nabi Muhammad SAW lalu Nabi mendengarkan dan membenarkannya jika ada kesalahan karena pada waktu itu belum ada bacaan dan para sahabat hanya fokus pada menghafal al-Quran dan belum mengerti membaca dan menulis, sedangkan dalam metode pembelajaran, Nabi Muhammad SAW lebih menggunakan metode talaqqi yang pertama, yaitu Nabi Muhammad SAW menyampaikan didepan para sahabat sedang para sahabat mendengarkannya (Zaujiyyah, 2010).

Nabi Muhammad SAW adalah sosok guru yang tidak bisa kita bantah kehebatan beliau dalam mengajar, cara beliau mendidik sehingga yang dulunya arab mekkah dikenal dengan ummi yaitu tak bisa membaca dan menulis, sampai pada masa kejayaan yang luar biasa (Ulwan, 2014). Beliau mempunyai semangat mendidik dan mengajar yang sangat luar biasa, bisa kita lihat di berbagai hadits Nabi Muhammad SAW (Farid, 2011).

Seperti dalam sebuah riwayat dari Abu Rifa'ah Tamim bin Usaid Radhiyallahu'Anhu berkata: "Aku berhenti di depan Rasulullah sedang beliau berkhutbah, maka aku berkata: Ya Rasulullah! Seorang lelaki asing datang bertanya tentang agamanya yang dia tidak mengetahui apa agamanya itu, maka Rasulullah menghampiriku dan meninggalkan khutbahnya, beliau berhenti di depanku, diberikan kepada beliau kursi lalu beliau duduk diatasnya, lalu beliau mengajariku apa-apa yang di ajarkan Allah kepadanya kemudian mendatangi khutbahnya lalu menyempurnakannya.

Demikian juga Rasulullah SAW memberi motivasi dan meningkatkan semangat para sahabat-sahabanya juga dilakukan dengan proses pembelajaran talaqqi oleh Rasulullah kepada sahabat-sahabatnya dimana Abu Hurairah Radhiyallahu 'anhu menceritakan bahwa Rasulullah SAW pernah bertanya.

Siapa diantara kalian pada hari ini yang puasa ? Abubakar Radhiyallahu 'anhu menjawab saya, Kemudian Rasulullah bertanya siapa diantara kalian yang hari ini mengantarkan jenazah? Abubakar Radhiyallahu 'anhu menjawab saya, Kemudian Rasulullah SAW bertanya lagi siapa diantara kalian pada hari ini telah memberi makan kepada fakir miskin, Abubakar Radhiyallahu 'anhu menjawab saya Rasulullah Sallallahu 'alaihi wasallam bertanya lagi, siapa diantara kalian yang menjenguk orang sakit ? Abubakar r.a menjawab saya lalu Nabi saw bersabda "tidaklah hal itu semua, berkumpul pada diri seseorang melainkan dia pasti masuk syurga". (HR. Muslim dan Al Bukhari)

Demikianlah dalam proses belajar talaqqi maka dengan mudah dapat dikontrol peserta didik juga sebagai adab bagi seorang pendidik dalam mengontrol anak-anak didiknya (Adawi, 2002). Secara khusus metode talaqqi dalam pendidikan adab ditemukan pada Kitab 'Uddatu At Talabi Binazmi Manhaji at Talaqqi Wa Al Adab yang di tulis oleh Syaikh Abdullah ibnu Muhammad su fyan al hakami dimana dalam kitab tersebut menjelaskan tentang metode talaqqi dan adab - adab para penuntut ilmu, sedangkan proses pendidikan dengan metode talaqqi dilakukan langsung kepada masyarakat diterapkan oleh Wahdah Islamiyah sebagai bagian dari pendidikan adab kepada ummat menjadi ummat yang utuh, sempurnah sebagai muslim yang kemudian di Wahdah Islamiyah menjadikannya sebagai Kelompok Kajian Islam (KKI) yang dilaksanakan secara terus menerus yang disebut Halaqah Tarbiyah yang dilakukan secara rutin dan berjengjang/bermarhalah. 
Oleh karena itu pada penelitian ini akan dikhususkan untuk melakukan survey terhadap pelaksanaan halaqah tarbiyah di Wahdah Islamiyah Sulawesi Tenggara dan Analisis kitab 'Uddatu At Talabi Binazmi Manhaji al-Talaqqi wa al-adab. Penelitian ini dilakukan dengan metode survey dan analisis literatur untuk melihat efektivitas pelaksanaan halaqah tarbiyah di Wahdah Islamiyah Sulawesi Tenggara.

\section{Pembahasan}

\subsection{Pelaksanaan Metode Pendidikan Talaqqi pada Halaqah Tarbiyah di Wahdah Islamiyah Sulawesi Tenggara.}

Wahdah islamiyah sebagai organisasi masyarakat berasaskan islam sangat konsen dan perhatian secara serius terhadap pembinaan dan pengkaderan ummat melalui kegiatan yang mengumpulkan masyarakat dengan jumlah tertentu dan diberikan pembinaan dan pendidikan secara terus menerus, berjenjang dan terkontrol serta dapat dievaluasi. Kelompok tersebut di beri nama halaqah tarbiyah karena membentuk kelompok yang jumlahnya tidak banyak setiap kelompok dan dibina oleh seorang ustaz sekaligus saudara yang disebut Murabbi, dalam proses tarbiyah itu menggunakan metode talaqqi.

Pendidikan adab dalam halaqah tarbiyah di Wahdah Islamiyah dilakukan dalam beberapa fase yaitu :

Pada fase awal, yaitu pada marhalah ta'rifiyah, maka tugas-tugas dan amanahamanah yang diberikan bertujuan untuk memberikan pemahaman dan pengenalan akan dakwah. Pengenalan tugas-tugas dakwah disesuaikan dengan perkembangan wawasan kader tentang dakwah. Hal ini dimaksudkan agar setiap kader dapat berinteraksi kedalam dakwah dengan baik dan dengan penerimaan yang baik. Hendaknya setiap murabbi dapat bersabar dalam memahami perkembangan pribadi kader (Wahdah Islamiyah, 2018).

Pada fase selanjutnya yaitu marhalah takwiniyah, tugas dan amanah yang diberikan bertujuan untuk memberikan orientasi dan metode operasional dakwah . Kader pada fase ini dibentuk dengan berbagai materi dan aktivitas yang tinggi sehingga setiap kader akan menemukan pola yang sesuai dengan dirinya dalam berinteraksi dengan dakwah. Dengan kata lain, kader akan mampu menemukan kapasitas pribadi mereka yang terbaik dalam dakwah; dan pada saat yang sama, mereka mampu menemukan pada bidang dakwah mana kemampuan mereka tersebut tepat disalurkan. Hal lain yang juga ditekankan pada fase ini adalah peningkatan kemampuan pribadi kader untuk mengelola problem-problem pribadi dengan baik agar kelak tidak menjadi masalah-masalah yang dapat menghambat operasional dakwah.

Jika kedua fase diatas berlangsung dengan harmonis, maka akan terbentuk pribadi kader yang dewasa dalam bergerak dalam dakwah. Mereka akan menjadi kader yang siap memikul amanah namun disertai kemampuan yang tinggi untuk menjalankannya. Pada fase ini kader sudah siap menerima amanaha dakwah

Pada fase tanfidziyah, seluruh tugas dilaksanakan dengan itqan (profesional) dan dengan semangat kejamaahan yang kuat. Tugas-tugas yang diberikan bertujuan membentuk spesialisasi dan profesionalisme dakwah sehingga seluruh kader pada fase ini mampu memberikan kontribusi yang maksimal dalam dakwah. Semua kader yang berada pada fase tanfidziyah memiliki amanah dakwah yang 
disesuaikan dengan kompetensi mereka baik didalam maupun diluar lingkaran lembaga dakwah.

Pada fase terakhir di sebut Fase Qiyadah yaitu kader yang berada pada fase ini dipersiapkan menjadi pemimpin dalam Wahdah Islamiyah (Islamiyah, 2018).

Gambaran efektivitas metode pembelajaran talaqqi pada pendidikan adab pada halaqah tarbiyah di Wahdah Islamiyah Sulawesi Tenggara dimana Survey penelitian dilakukan pada 191 sample dengan sampel yang diteliti adalah para murabbi se-sulawesi tenggara:

1. Masih banyak jumlah halaqah tarbiyah yang pesertanya tidak hadir semua pada saat tarbiyah yakni terdapat 44 persen;

2. Masih ada peserta tarbiyah yang tidak mengikuti proses tarbiyah (Proses pembelajaran) sampai selesai yakni 10 persen;

3. Masih ada mutarabbi/yah yang tidak bertahan sampai tarbiyah selesai pada saat itu yakni terdapat 4 persen;

4. Setelah menjalani satu tahun tarbiyah maka mutarabbi/yah tidak lagi sama jumlahnya seperti pada saat akan memulai Tarbiyah yakni terdapat 75 persen;

5. Setiap tarbiyah menggunakan waktu lebih dari 1 jam;

6. Masih ada halaqah tarbiyah yang belum melaksanakan tarbiyah secara rutin yakni sebesar 8 persen;

7. Masih ada mutarabbi/yah yang tidak senang dalam menjalani proses tarbiyah yakni sebesar 2 persen;

8. Semua mutarabbi/yah serius dalam menyimak materi tarbiyah;

9. Tidak semua mutarabbi/yah mengikuti ujian kenaikan marhalah pada saat yang bersamaan yakni masih terdapat 56 persen;

10. Masih ada mutarabbi/yah yang tidak naik tingkat pada saat ujian yaitu terdapat 37 persen.

Dari hasil survey pelaksanaan metode pendidikan talaqqi pada halaqah tarbiyah di Wahdah Islamiyah di temukan bahwa efektifitas belum tercapai.

\subsection{Metode pendidikan talaqqi pada kitab "uddatu At tolabi binazmi manhaji At talaqqi wa al adab". \\ Adapun konsep talaqqi yang ditemukan dalam kitab "Uddatu At Talabi Binazmi Manhaj At Talaqqi Wa Al Adabi” karya Syaikh 'Abdillah Ibni Muhammad Sufyan Al Hakimi adalah : \\ a. Bergabung dengan halaqah pendidikan adab (indam ila halqihi ta'lim al adabi)}

Bergabung dengan halaqah adab adalah sesuatu yang sangat penting un tuk dilakukan dalam rangka mewujudkan efektivitas metode pendidikan talaqqi ini dilakukan agar perjalanan proses pendidikan dapat dikontrol dengan baik, dapat dievaluasi secara berkesinambungan dan dapat diadakan penyesuaikan metode pembelajaran.

\section{b. Membangun sistem pendidikan adab (bina'u nizaami ta'limin mutahadiran)}

Islam adalah merupakan sistem yang sempurna. Di dalamnya terdapat aturan yang mengatur segala bentuk interaksi antar sesama manusia, seperti sistem sosial, ekonomi, politik, pendidikan dan semua bentuk kehidupan lainnya. Sistem dalam islam mengatur semua bentuk aktivitas manusia mulai dari tidur sampai bangun tidur kembali, mulai dari hal-hal yang sangat kecil sampai hal 
yang sangat besar, termasuk pendidikan harus memiliki sistem pendidikan yang profesional untuk mewujudkan insan adabi.

\section{c. Menetap di masjid selama Talaqqi ( Al Baqa fi al Masjid Atsna at Talaqqi)}

Ketika Nabi Muhammad SAW tiba di madinah tahun $622 \mathrm{M}$, bertepatan pada bulan rabi'ul awal tahun pertama hijriayah, beliau membangun sebuah masjid, yang sekarang dikenal dengan nama Masjid Nabawi -atau lebih dikenal masjid Madinah yang terletak di pusat madinah dibangun di sebuah lapangan yang luas. Di Masjid Nabawi, juga terdapat mimbar yang sering dipakai oleh Nabi Muhammad saw. Masjid Nabawi menjadi jantung kota Madinah saat itu. Masjid ini digunakan untuk kegiatan politik,diskusi, perencanaan kota, menentukan strategi militer, dan untuk mengadakan perjanjian termasuk tempat memberikan pendidikan kepada para sahabat-sahabat RA. Oleh karena itu menetap dan tinggal di masjid selama proses pendidikan adab adalah merupakan warisan Rasulullah SAW yang harus di lanjut dan merupakan bagian dari metode pendidikan talaqq pada pendidikan adab..

\section{d. Mulazamah (AI mulazamath/Tinggal bersama Guru)}

Mulazamah, sistem pendidikan berkualitas ala Salafushalih. Istilah ini kemudian kita dapat orientasikan kepada metode belajar pendidikan non-formal yang dilakukan di markaz-markaz pendidikan yang dibuat secara khusu sehigga guru dan para penuntut ilmu menetapi dan tinggal bersama dalam rangka mempelajari suatu ilmu. Metode mulazamah ini menjadi metode yang digemari oleh para penuntut ilmu generasi awal umat ini. Metode mulazamah menggunapan prinsip tinggal bersama dengan guru dalam waktu yang cukup lama hingga ilmu yang dipelajari dapat dikuasai dan dapat diajarkan kepada ummat.

\section{e. Menghafal ilmu (Hafzul IImi)}

Menghafal adalah merupakan langkah awal yang harus di lakukan oleh para penuntut ilmu, dilakukan di waktu dhuha, duduk menghafal ilmu dengan penuh kesabaran, bersabarlah nanti kamu akan menjadi penghafal yang mapan.

Pentingnya menghafal ilmu bagi para penuntut ilmu terutama dalam menghafal Al-Qur'an dan Hadits. Karena tradisi keilmuan islam adalah dengan mempelajari ilmu melalui proses hafalan, hal ini yang telah diajarkan oleh Nabi Muhammad SAW. dalam mengajarkan para sahabatnya, hingga generasi tabi'in masih banyak yang menggunakan menghafal sebagai proses menjadikan pribadi yang berilmu.

Dalam Mukaddimahnya imam Ibnu Jauzi mengatakan, "Sesungguhnya Allah SWT mengistimewakan umat kita dengan menghafal Al-Qur'an dan IImu. Umat sebelum kita juga membaca kitab mereka yang terdapat dalam lembaranlembaran, akan tetapi mereka tidak mampu menghafalkannya.

\section{f. Menghormati guru/Syaikh secara khusus (ihtarim ala al mudarris)}

Ini adalah pelajaran sekaligus perbuatan yangn harus dilakukan oleh penuntut ilmu di majelis ilmu karena sesungguhnya didalam majelis itu adalah kebenaran.

Penghormatan terhadap syaikh merupakan cerminan keagungan islam yang menghormati kedudukan para guru selain itu, kita juga dianjurkan tawaduk kepada nabi, ulama, orang tua, guru. Ini bermakna bahwa tawaduk merupakan suatu akhlak mulia. Suatu yang mulia (ilmu dan profesi guru), hanya kita peroleh melalu i tawaduk 
Imam Az-Zarnuzi mengatakan, penghormatan itu lebih utama daripada ketaatan. Menurutnya tidakkah kita melihat bahwa seseorang tidak kafir dengan kemaksiatan dan dapat kafir dengan meninggalkan penghormatan (Zarnuzi, 2019).

\section{Kesimpulan}

Metode talaqqi sebagai model pendidikan dan pembinaan dalam islam juga di lakukan oleh masyarakat untuk mendidik ummat, mentarbiyah, mentazkiyah dan mentaklim masyarakat, karena itu kelompok - kelompok masyarakat memilih jalan ini untuk membangun peradaban islam di masa yang akan datang karena peradaban islam yang gemilang di masa yang akan datang tidak akan terwujud tanpa ada usaha keras dari ummat islam,

Wahdah Islamiyah sebagai organisasi masyarakat berasaskan islam sangat konsen dan perhatian secara serius terhadap pembinaan dan pengkaderan ummat melalui kegiatan yang mengumpulkan masyarakat dengan jumlah tertentu dan diberikan pembinaan dan pendidikan secara terus menerus, berjenjang dan terkontrol serta dapat dievaluasi. Kelomok tersebut di beri nama halaqah tarbiyah karena membentuk kelompok yang jumlahnya tidak banyak setiap kelompok dan di bina oleh seorang ustaz/syaikh/guru sekaligus saudara yang disebut Murabbi, dalam proses tarbiyah itu menggunakan metode talaqqi .

Dari hasil penelitian survey metode pendidikan talaqqi pada halaqah tarbiyah di Wahdah Islamiyah Sulawesi Tenggara dan kitab 'Uddatu th alabi binazmi manhaj talaqqi wal adabi maka di rekomendasikan pengembangan metode pendidikan talaqqi pada halaqah tarbiyah di Wahdah Islamiyah Sulawesi Tenggara sebagai berikut:

1. Membangun sistem pendidikan talaqqi pada halaqah tarbiyah di Wahdah Islamiyah,

2. Mengembangkan sistem belajar mulazamah pada beberapa kalangan di Wahdah Islamiyah,

3. Mengembangkan sistem penguatan hafalan pada peserta halaqah tarbiyah, 4. Membangun kebiasaan yang mengedepankan adab dan penghormatan kepada murabbi.

Jadi adapun kesimpulan hasil penelitian ini adalah untuk mencapai efektivitas pelaksanaan tarbiyah di wahdah islamiyah sulawesi tenggara, maka harus dilakukan kombinasi antara standar operasional pelaksanaan tarbiyah di wahdah islamiyah dan konsep manhaj talaqqi dalam kitab "Uddatu at talabi binazmi manhaj at talaqqi wa al adabi

\section{Daftar Pustaka}

Abdullah, M. sufyan A. H. (1429). 'Uddatu Talabi binazmi manhaj at talaqqi wa al adab.

Adawi, M. Al. (2002). Tarbiyatil abna': Bagaimana nabi mendidik anak. Media hidayah.

Al-Gazali, M. (2005). Ayyuhal walad: irsyad baitus salam.

Farid, A. (2011). At tarbiyah ala Manhaji Ahlissunnah wal Jamaah. Elba Fitrah Mandiri Sejahtera.

Islamiyah, W. (2018). Panduan Diklat Murabbi Wahdah Islamiyah. Wahdah Islamiyah. Ulwan, A. N. (2014). Pendidikan anak dalam islam (Tabiyatul aulad fil islam). Insan Kamil. Zarnuzi, A. (2019). Ta'lim Muta'alim. Aqwan Media Profetika.

Zaujiyyah, I. qayyim Al. (2010). Tuhfatul mauduud bii ahkami al mauluud (hanya untukmu 
anakku, panduang lengkap pendidikan anak sejak dalam kandungan hingga dewasa. Pustaka Imam Syafi'i. 